\title{
La mitología en la poesía de Guillermo Valencia
}

$\mathrm{E}$ NTRE todos los poetas modernistas hispanoamericanos se destaca el colombiano Guillermo Valencia ( 1873 -1943) como estudioso de las lenguas y literaturas clásicas, el griego $y$, sobre todo, el latín. Empezó estos estudios a muy tierna edad, aprendiendo junto a su padre, "varón de limpia prosapia moral, los símbolos de la ética y las sutiles telarañas del alfabeto griego y latino. Bebió el vino de los clásicos en su cáliz de infancia". ${ }^{1}$ Terminados sus años escolanes en el Seminario de Popayán, el joven Valencia ya poseía una cultura clásica más sólida que la mayoría de los poetas modernistas hispanoamericanos, ${ }^{2}$ que sólo conocían el mundo clásico a través de traducciones y de otras literaturas, la española y la francesa. ${ }^{3}$ Valencia fue "un greco-latino auténtico, queremos decir, de primera mano, con erudición tomada en las fuentes originales, y con

1 María Hortensia Lacau, "Guillermo Valencia", Nosotros, XXIII (1943), 167-168.

2 Lacau, págs. 171-172, dice: "Valencia es un poeta modernista con caracteres propios. ¿Cuáles son éstos?... Raigambre clásica por su conocimiento y acendrado amor de las literaturas latina y griega. Esta identificación espiritual, sobre todo con la lengua latina, la encontraremos objetivada a lo largo de su obra. Valencia sabía latín y no 'latines'". Leopoldo Lugones es otro modernista que conocía las literaturas clásicas en sus lenguas originales. Hasta llegó a traducir al castellano los trozos de la Ilíada que fueron publicadas con un romentario en prosa en dos volúmenes, Estudios belénicos (1924) y Nuevos estudios belénicos (1928). Y lo más sorprendente es que no comenzara a estudiat el griego hasta tener los cuarenta años, según Baldomero Sanín Cano, en "Lugones ha muetto", Nosotros, VII (1938), núm. extraordinario, pág. 340 .

3 Otra fuente importante de cultura clásica, y especialmente para la mitología, fue el arte. "Mi museo ideal", diez sonetos por Juliáa del Casal, acusan el fuerte influjo de los cuadros mitológicos del pintor francés Gustave Moreau. Rubén Dario aprendió mucha mitología de los pintores franceses e italianos y también de la obra de mitólogos como Ménard, Mythologie lans l'art ancien et moderne, como ha probado Arturo Marasso Rocca en su sesudo estudio Rubén Dario y su creación poética ( La Plata, 1934). 
una clara intuición del espíritu que animaba a las sociedades antiguas"." Esta cultura clásica está presente en toda la obra poética de Valencia. Durante su vida, el vate colombiano publicó sólo una colección importante de versos originales, Ritos ( $\mathrm{I} 898$ ). ${ }^{5}$ Estos poemas tienen mucho de lo parnasiano en su plasticidad y colorido, con influencias de modelos franceses tales como Leconte de Lisle y Heredia. Según las generales tendencias del modernismo finisecular, hay en este volumen abundantes referencias a la mitología clásica. Casi una cuarta parte de los poemas de Ritos contienen referencias o temas mitológicos.

En el soneto "Pigmalión", Valencia describe gráficamente el célebre mito del escultor:

En líbico marfil tallas tu sueño de amor, la ninfa que tu ser exalta, y entre labios de olímpico diseño flores de perla tu buril esmalta.

Sufres; el bloque de mirar risueño donde la fiebre de la vida falta yace inmóvil: la sangre de tu dueño bajo las curvas gélidas no salta. ${ }^{6}$

En el sexteto de este bello soneto vemos cómo se transforma la ninfa de piedra en una mujer encantadora de carne y hueso:

Atiende el cielo tu clamor. "Resurge", Apolo clama; la beldad esquiva tórnase carne y a la vida surge;

la besas bajo el ático plafondo, y entre la red de su pestaña viva hallas lo azul sin límite ni fondo... (63)

Los dioses han escuchado con simpatía la petición del escultor y se la han otorgado, pero aquí es Apolo el que realiza esta maravillosa metamorfosis, y no Afrodita, como en la mayoría de las versiones del mito. ${ }^{7}$ En el mito clásico Pigmalión se casa con la hermosa mujer creada del

4 Rafael Maya, Estampas de ayer y retratos de bov (Bogotá, 1954), pág. 251.

5 Ritos fue reimpreso y ampliado con el nombre de Poemas (México, 1917; Buenos Aires, 1918) y Sus mejores poemas (Madrid, 1919). En 1929 Valencia publicó Catay, una colección de traducciones de poetas chinos. En 1948 salió la edición de Aguilar, Obras poéticas completas, que incluye traducciones y versiones de muchos poetas y también gran número de poemas ocasionales.

6 Valencia, Obras poéticas completas (Madrid, 1948), pág. 63. De aquí en adelante las citas de Valencia proceden de esta edición, indicándose entre paréntesis en el texto la pág. de que proceden.

7 Compárese con Ovidio, Las metamorfosis, X, fábula 9. 
mármol y de ella tiene un hijo llamado Pafos. Valencia sólo sugiere esto de un modo ambiguo cuando dice en el último verso que "hallas lo azul sin límite ni fondo", es decir, un estado de alegría y contento con la estatua-mujer.

" OOh Paganismo!" es otro soneto de Ritos que revela la afición de Valencia por el mundo clásico. Como es de suponer, también aquí el poeta se sirve de alusiones mitológicas:

que Apolo tienda el arco de punta voladora

y el éter cruce alada la flecha de Cupido. (55)

En "Turris Eburnea" grita el poeta a la torre de marfil que le abra sus puertas. Alli puede descansar seguro, lejos de los hombres y las feas realidades de la vida. Valencia se dirige a la Belleza que vive en esa torre:

$$
\begin{aligned}
& \text { yo - como el ave que Minerva escuda- } \\
& \text { quiero en la lumbre de su faz radiosa } \\
& \text { iapacentar mis círculos de fuego! (61) }
\end{aligned}
$$

"Homero" es otro poema que contiene varias alusiones mitológicas bien escogidas:

$$
\begin{aligned}
& \text { sueltas de Aquiles la pasión bravía, } \\
& \ldots \ldots \ldots \ldots \ldots \ldots \ldots \ldots \ldots \ldots \ldots \ldots \\
& \text { verde corona tu perfil ensancha, } \\
& \text { y vas - manso cantor de lo divino- } \\
& \text { asido al brazo mórbido de Helena... }
\end{aligned}
$$

La más llamativa se refiere a Eurímaco, uno de los principales pretendientes de Penélope durante la larga ausencia de su marido. Al volver a su tierra después de tantos años, Ulises le mata:

$$
\begin{aligned}
& \text { y los ojos de Eurímaco vidría } \\
& \text { la saeta de Ulises vengadora. }{ }^{8} \text { (62) }
\end{aligned}
$$

Valencia dedica un poema de tres sonetos a Ovidio en su triste destierro en Tome. El poeta latino, añorando su país,

8 Compárese con Homero, La Odised, XXII: 88, donde Ulises le dirigió a Eurímaco una saeta: " ... acertándole en el pecho junto a la tetilla, le clavó en el hígado la veloz flecha. Cayó en el suelo la espada que empuñaba Eurímaco y.. por fin, obscura nube se extendió sobre sus ojos." 
Pide a Jove una ráfaga de lumbre para triunfar sobre el nevado bloque; pámpano fresco que el erial retoque y peplo azul para la gris techumbre;

fuentes'de juguetona muchedumbre de Náyades el Sátiro convoque,

pero el Numen desoye su lamento y "le mira sin cesar con ceño adusto" (59).

La figura bíblica de Moisés es el tema de dos sonetos. ${ }^{9}$ Mientras canta las glorias del imponente judío, Valencia le da atributos de dioses paganos:

y de su añosa barba las vívidas alburas

la majestad le dieron de un Hércules vetusto.

¡Salve pujante macho! Vigor de primavera erige en altas curvas tu carne floreciente, y porque al mundo asombre tu ancianidad de fiera

a Pan de Arcadia robas el nimbo de tu frente.

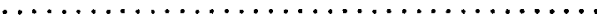

$y$ en ti destella el Fauno de la pagana gente. (66-67)

Sin duda alguna el poema mitológico más significativo de la obra poética de Valencia es "San Antonio y el centauro". Antes de empezar el poema, cita el autor un largo párrafo de la obra latina In vita Sancti Pauli eremitale, de San Jerónimo, que describe el breve encuentro de San Antonio con el centauro mientras iba aquél en su camino a visitar a San Pablo. Se detiene San Antonio a preguntarle al monstruo por dónde está el camino. El centauro se lo señala, balbuciendo unas palabras incoherentes, y luego desaparece. Valencia desarrolla y agrega muchos detalles de propia invención a esta sencilla escena, haciendo de ella un diálogo filosófico entre el Santo y el centauro, y aprovecha la oportunidad para contrastar y parangonar la cristiandad y el paganismo. Comienza el poema presentándonos la solitaria figura del monje que atraviesa el desierto. Súbitamente, oye un rumor lejano y ve aparecer en el horizonte la extraña forma del centauro que viene derecho a su encuentro:

9 Según Sonja Karsen, Guillermo Valencia. Colombian Poet (New York, 1951), pág. 74, la célebre estatua marmórea de Moisés hecha por Miguel Ãngel le inspiró a Valencia estos versos. 
... desmelenado, inquieto, se para. El ermitaño y el monstruo se interrogan, y así, bajo la calma de la noche, dialogan: (104)

El centauro se identifica en estos primeros versos del diálogo como "el viejo Hippofos: el último Centauro / que circundó sus sienes con el augusto lauro / crecido entre las grutas del sagrado archipiélago"; y se jacta de sus fuerzas y poderes sobrehumanos de una manera algo extravagante:

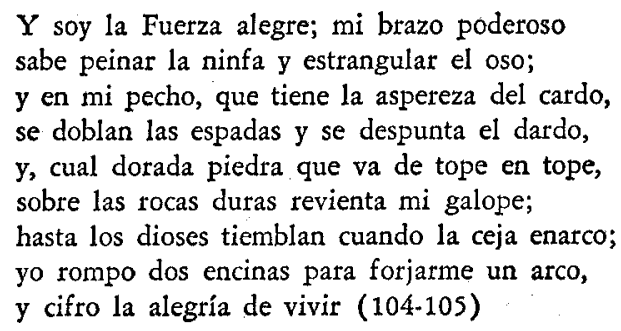

Estos detalles, por extremo vanidosos, no son del todo fantásticos: según los autores de la antigüedad, los centauros eran muy fuertes y fieros. Homero los representa llevando una vida salvaje y bestial (Ilíada, I, 268; Odisea, XXI, 295). Sófocles dice que no puede acercarse a estos seres rudos, "sin pares en fuerza" (Tracbinae, r095), y otros muchos escritores griegos y romanos describen detalladamente su gran vigor $y$ violenta naturaleza. ${ }^{10}$

Amén de estos atributos de fuerza puramente física, el centauro entraña otros rasgos importantes: semidiós, humano-equino-divino, este ser mitológico es símbolo aquí del paganismo quintaesenciado, según sus propias palabras:

\author{
... Soy un hombre \\ que sueña, quiere y puede, y a la par lleva nombre \\ de monstruo; tengo mente y endurecido callo: \\ soy malo como el hombre y ágil como el caballo, \\ y velo extraño símbolo, Soñador y lascivo, \\ quien conozca mi esencia conoce un adjetivo, \\ comprende el adjetivo universal y humano \\ que entre su seno oculta la palabra ;Pagano! (105)
}

$10 \mathrm{~V}$. Ovidio, Las metamorfosis, XII, 210 v siguientes; Apolodoro, II, 5:4; Diodoro, IV:12; Pausanias, V, 19:2; V, 10:2. 
Por fin le toca la palabra al santo. Este le dice al centauro que es un humilde sirviente de Dios que predica la gloria de Cristo. Vuelve a hablar el centauro con un panegírico dedicado a Apolo. Estos versos, pletóricos de alusiones al dios pagano, demuestran el profundo conocimiento de la mitología clásica por parte de Valencia:

No puede vuestro Cristo competir con Apolo, con el hijo soberbio del Ceñudo y Latona, que en los brazos de Dafnis se abandona (105)

Según el renombrado historiador griego, Diodoro (Biblioteca bistórica, IV: 84), Dafnis, a quien se le atribuye la invención de la poesía bucólica, fue el hijo de Hermes y una ninfa. El mito corriente de Dafnis narra que su amante, una bella ninfa muy celosa, le metamorfosea en piedra al enterarse de su perfidia con otra. ${ }^{11}$ Valencia parece conocer otra versión menos difundida que se refiere a Dafnis como el amado de Apolo. Cuenta este mito que la madre del joven le puso cuando era muy niño en un lauredal. Por eso se le llama Dafnis y por eso es un favotito de Apolo, ${ }^{12}$ que amaba a Dafne, la ninfa convertida en laurel.

El centauro sigue la alabanza de Apolo con varias alusiones a él como dios del sol con su nombre de Febo, y también menciona su atributo como arquero de los cielos:

$$
\begin{aligned}
& \text { o lleva el ígneo carro que volcó Faetonte } \\
& \text { por los campos azules del abierto horizonte. } \\
& \text { El olímpico auriga de la eterna carroza } \\
& \text { donde Febo, ceñido de laureles, retoza } \\
& \text { con las Horas desnudas, los sonoros tropeles } \\
& \text { por cl éter dirige de sus raudos corceles. } \\
& \text { Van cayendo las sombras bajo el dardo certero } \\
& \text { del Arquero divino; por el ancho sendero } \\
& \text { que siguió la carroza, cruza el sol, pasa el día, } \\
& \text { y la luz va regando su dorada armonía (105-106) }
\end{aligned}
$$

En la siguiente estrofa el centauro canta a Apolo como "padre del Verso". Aquí alude al mito de Marsias, el célebre músico, hábil tocador de flauta, que se atrevió a desafiar a Apolo con dicho instrumento. Las Musas declararon vencedor a Apolo, el dios ató a Marsias a un árbol y lo desolló vivo para castigarle por su temeridad. La referencia de Valencia es económica y gráfica:

11 Las metamorfosis, IV:275.

12 Servio. X. 26; VIII. 68. 
De allí parten los yambos como flechas de enojo

del artista con celos que, siguiendo la huella

de Marsyas, lo cautiva, lo vence, lo desuella. (106)

Termina este himno apolónico con alusiones a Musagetes (Apolo), dios de los poetas y las Musas, y una descripción de la belleza física de Apolo. Los últimos versos de este pasaje sugieren escenas de placeres sensuales: un erotismo rubendariano:

Por la senda más agria del adusto Parnaso, con la crin en desorden, a la luz del ocaso va subiendo Pegaso portador en sus ancas del cantor Musageta de las Vírgenes blancas. $Y$ en la fiesta del mármol, sobre el bajo relieve, entre dioses risueños y Afroditas de nieve cuyas bocas ensayan las sonrisas cternas, se irgue Apolo: la carne de sus pálidas piernas; el torso alabastrino donde la gracia ondula en cadenciosos planos; la frente que simula un ara donde ofician la Luz y la Alegría, y de su cuerpo todo la vívida armonía parece que suspiren por el febril contacto ¡de efebos y de ninfas de delicioso tacto! ¡Al Crinado cantemos! (106)

Todo este bello encomio al dios pagano no le ha impresionado gran cosa al monje, que ahora relata la vida y la crucifixión de Jesucristo. Mientras habla San Antonio, el centauro repentinamente se aleja "doliente y silencioso", convencido, al parecer, de la grandeza del dios cristiano:

$y$ entre la gris llanura

borró para los hombres su helénica figura, mientras el viejo monje-con su báculo inciertocon el signo de gracia borraba en el desierto las huellas del Centauro... (109)

Así termina el poema. El ideal cristiano vence el pagano. Pero no hay ninguna desaprobación del pagano, ni mucho menos, porque en la cálida descripción de Apolo, Valencia revela su gran admiración por la antigüedad y su mitología.

Un crítico ha dicho de este poema: " . . one is at a loss to find to what side Valencia is inclined, whether to Christ's or Apollo's". ${ }^{13}$ Otros opi-

13 A. Ortiz Vargas, "Guillermo Valencia, Colombia's Master Poet", Poet Lore, XLI (1930), pág. 421. 
nan de distinta manera. ${ }^{14}$ Pero nadie niega la erudición mitológica en "San Antonio y el centauro". Daniel Restrepo, que pone casi toda su atención en el aspecto cristiano del poema y hace digresiones para probar la fe católica de Valencia, dice de paso:

Lo primero que sorprende en esta creación de nuestro Maestro Colombiano, es la erudición helénica. La primera parte del poema supone un dominio de la mitología cual no es fácil hallar en los poetas neoclásicos del siglo xvIII, enamorados de las deidades paganas, y tan estériles cuanto amanerados en sus concepciones. El cuadro que Valencia dibuja de la cultura pagana, es de una comprensión admirable: es un resumen expresivo de la mentalidad, de los sentimientos, de las supersticiones y de los vicios de Grecia... Erudición griega es el empleo de nombres como "Hippofos", "Marsyas", "Orcomenio", "El Ceñudo y Latona".15

"San Antonio y el centauro" recuerda algo el famoso "Coloquio de los centauros" de Rubén Darío, aunque los dos poemas en verdad tienen poco en común. Ambos tratan de centauros y están en forma dialogada. Pero el poema rubendariano hace hincapié en los mitos que tienen que ver con los centauros e incluye disquisiciones que ahondan en los misterios de la vida y la muerte; en el poema de Valencia las alusiones mitológicas casi todas se refieten a Apolo, aunque el centauro, al empezar el diálogo, narra algo de su vida y carácter. Valencia habrá tomado la idea para este diálogo entre el santo y el centauro del libro de San Jerónimo, pero también puede que el "Coloquio de los centauros" publicado en Prosas profanas (1896), unos pocos años antes de Ritos, le haya inspirado.

En otras poesías de Ritos y a través de toda la poesía miscelánea de Valencia, recogida y publicada en la edición de Aguilar, ocurren alusiones a la mitología clásica, unas comunes a todos los poetas, otras de más originalidad e imaginación. La titánica figura del poeta francés, Víctor Hugo, le inspira un poema a Valencia como a tantos poetas hispanoamericanos. Aquí en estos versos el colombiano le parangona al vate gálico con varias deidades paganas: Hefestos, el herrero de los dioses, y el Cí-

14 V. Daniel Restrepo, "San Antonio y el centauro", Revista Javeriana, XXX (1948), 226-232. Lacau, obra citadd, sostiene: "El sentimiento religioso vive en muchas concepciones poéticas de Valencia. Algunos críticos han señalado en él una fluctuación entre la admiración pagana y el sentimiento cristiano. Creemos que tales críticas son injustificadas. Puede admirarse el ideal estético, pagano, pero aceptarse como raigambre de la vida perdurable la doctrina de Cristo. Además el propio Valencia falla su pleito, en forma definitiva, en su hermoso poema "San Antonio y el centauro" (págs. 172-173).

15 Restrepo, págs. 226, 231. "Latona" no es precisamente ejemplo de erudición griega, como dice Restrepo, sino latina, porque es el nombre que le dieron los romanos a la madre de Apolo, "Leto" en griego. 
clope; también aparecen otras referencias mitológicas, en especial el laurel de Apolo (la rama luminosa), símbolo de la poesía que sirve de leitmotiv en estas líneas:

La negra ferrería

resuella por los hornos fatigosa,

y al golpe de martillo

salta la luz en chispas deslumbrantes;

alli, el mítico Hefestos,

¿quién forjará tus versos centelleantes,

ceñida la ancha frente, de Apolo con la rama luminosa?

Pedían tus martillos

puños de Prometeos y de Atlantes;

hoy, cabe el yunque mudo,

se arremolina multitud llorosa;

has escalado el cielo - ceñido con la rama luminosa-

amontonando versos,

versos como el Pelión de los gigantes

.............................

y tú, desde la cima,

en las garras de un águila, rampantes

muestras - potente Cíclope-

el fuego de tus himnos fulgurantes,

ceñido la ancha frente, ; de Apolo con la rama luminosa!

(553-554)

Quizás la comparación que acuda con la frecuencia más fatigosa a la pluma de los poetas en cuanto a Hugo es la de Júpiter o Zeus con sus rayos. ${ }^{16}$ Valencia no la emplea en el poema citado, pero sí en otro, "La tristeza de Goethe", donde interpreta la filosofía y personalidad del alemán y le presenta como numen digno de compararse con el dios pagano en varios aspectos:

Al descorrer el velo que recataba el busto, te ves, oh Goethe, un numen de fascinar sereno, y lloras ante el mármol, tú, iJúpiter venusto! grave, feliz, remoto, primaveral, augusto, del águila invisible y encadenado trueno.

Del ario Jove tienes la majestad austera

16 Compárese con los versos de Dario dedicados al poeta francés: "y Júpiter Tonante, / que manda el aquilón, domeña el rayo, / que a su voz el Olimpo temblar hace, / y sé que ostenta, con su manto de éter, / en un trono flamígero y radiante"; (Obras poéticas completas [Madrid, 1941], pág. 166), o éstos de Salvador Díaz Mirón donde Hugo aparece como Titán que desafía el poder de Zeus: "¿Qué fuerza más divina / que la de ese Titán que escala el cielo, / desafiando al rayo" (Poesias completas [México, 1941], pág. 34). 
— también a ti por Júpiter te consagró la Fama-.

En ti todo transpira la olímpica clemencia, la plenitud, la firme serenidad, la ciencia, el pecho sin la angustia de sórdidas perfidias, la paz inaccesible, la material esencia: ¡Tú fuiste la viviente divinidad de Fidias! (614-615)

En esta alabanza goethiana una referencia lacónica:

su primordial enigma narráronte las piedras (615)

parece referirse al mito de Deucalión y Pirra, los únicos humanos en la mitología griega que se salvaron del diluvio y que volvieron a poblar la tierra, arrojando por encima del hombro piedras que se convertían en hombres y mujeres.

Goethe, $\tan$ divino cantor para Valencia, escribe poemas llenos de color y música. No sólo le arrebata a Júpiter el cetro, sino que les quita a otras figuras mitológicas los dones: a Orfeo y a Apolo (el Crinado) la música y a Febo el sol de muchos colores:

Arrebataste al Febo su veste policroma y sus veloces flechas la asiste en rudos vuelos. (616)

Si arrebataste a Júpiter el cetro de la vida, sus símbolos a Orfeo, su citara al Crinado; si a tu vivir le diste la exaltación panida, y por templar las hieles del implacable hado vaciaste de Dionisos la copa enloquecida: (618)

El colombiano sentía por la obra de Goethe una grande admiración, como notamos en los versos ya citados y que se nota también en una explicación en prosa que sigue a "La tristeza de Goethe" (622-624). Una de las cosas que le hizo más simpático fue ese amor profundo por lo griego que para Goethe "encerraba el proceso humano; es decir, un mundo" (624). Valencia, que era un buen traductor de muchos poetas de varias lenguas, tradujo al castellano unos veinte poemas de Goethe, entre ellos algunos que tratan de temas mitológicos como Ganimedes (806) y Prometeo a Pandora (810).

La heroica y doliente figura de Prometeo aparece en los versos de Valencia, especialmente en los de tono religioso, como "Job":

Su lacerada carne despréndese a pedazos

bajo los picotazos de un buitre, 
par de aquél que sobre un monte

-ya hendido el pecho-

le sorbió la sangre rebelde a Prometeo. (576)

En "Loa del pobrecillo" alude Valencia a San Francisco de esta manera:

\section{Dulce Prometeo}

que robaste al cielo la demente llama, has cobrado imperios al Señor divino $y$ en fulgor eterno dora tu camino la febril antorcha que tu ser inflama. (562)

Dos veces hay alusiones a Narciso, una en "A Julio Flórez":

Tu libro a nuestras almas es el bruñido espejo que deleitó a Narciso doblado ante el raudal (547)

Más impresionante es la siguiente imagen en "A mis votos", versos dedicados a unos jóvenes recién casados:

surja del fondo especular su fresca imagen cual si fuese

la de un Narciso de doble faz, (432)

"Esculturas" fue escrito en la ocasión de otras bodas. Después de describir a la novia, recurre Valencia a la mitología para comparar al novio con dos dioses griegos:

Para contraste de ese albor divino, quiero fundir en bronce rutilante un mancebo que sea a un tiempo Atlante y Hermes, pero en consorcio peregrino.

De aquél le doy el ademán felino bajo la mole en gravedad constante; del otro la mirada penetrante que disipa las sombras del camino...

Esta última alusión a Hermes como Dios de los caminos que protege a los viajeros atestigua otra vez el sólido conocimiento mitológico de Valencia. En la obra de otros muchos poetas hispanoamericanos de su época 
hay referencias a Hermes sólo como el mensajero de los dioses o el guía de las almas muertas. ${ }^{17}$

En "Elegía", poema dedicado a un perro fiel, Valencia se vale de los canes mitológicos, la jauría de Diana y el monstruo de tres cabezas, guardián inflexible de los infiernos:

¿Por qué no celebrarte en el postrero vástago de tu raza corte de Diana, prole de Cerbero? (603)

Pan, dios tan preferido de Darío y otros modernistas, no está ausente de la obra de Valencia. En "La Voz en el eco" vemos bien delineados los rasgos físicos de los faunos:

Inútil perseguiir el atávico signo que velan tus mechones, porque tu aire maligno a todos muestra el sello de prosapia faunesca:

Si alguien duda, remire tus perfiles de cabro, y verá cómo brilla sobre tu rostro glabro la luz de aquella gracia conturbadora y fresca. (684)

Es probable que "el atávico signo" que velan los mechones sean las orejas, aunque puede referirse también a unos pequeños cuernos, porque muchas veces, sobre todo en el arte, se le representa a Pan con los cuernos del chivo. El uso del adjetivo "glabro" también está conforme con el retrato de Pan de la antigüedad: aunque posee cuernos cabrunos, tiene la cara lampiña de un joven.

Luego sigue el poeta con una descripción de Pan y sus seguidores que bailan y cantan celebrando sus ritos:

En la arcaica siringa, tubular, nemorosa, cantaste el himno alado del amor y la vida y a tu vivo conjuro dejaron la escondida mansión faunos y ninfas en ebriedad gozosa.

17 En la obra poética de Darío, riquísima en alusiones mitológicas, escasean las alusiones a Hermes. Darío siempre le llama por su nombre romano, Mercurio. Su insignia, el caduceo, aparece en casi todas las referencias a este dios: "En tu homenaje pasar veo / a Mercurio y tu caduceo" (Obras poéticas completas, pág. 769); "Parece que Mercurio llevara el caduceo / de manera triunfal en mi dulce país" (pág. 755); "y vi la singular doble serpiente / que enroscada al celeste caduceo / pasó sobre las olas de repente / llevada por Mercurio" (pág. 646). En "Canción de los pinos". alude Darío a la famosa sandalia de Mercurio: "Tocó vuestra frente la alada sandalia" (pág. 656). 
Tú al centro, ellos tejían su danza voluptuosa por restaurar el mito de una estirpe abolida, y así pareció el numen de la selva flotida, con sus labios sedientos y su mirar de diosa. (685)

Es curioso reparar en que la mayoría de las alusiones mitológicas en la obra poética de Valencia se refieren a dioses masculinos como Pan, Júpiter, Apolo, Prometeo, Hermes, el centauro; las diosas o mujeres célebres de la mitologia no aparecen con la misma frecuencia en ella. Aunque hay muchos poemas de Valencia dedicados a mujeres, por lo general, el poeta no ha buscado un paralelo mitológico al hablar de ellas. La única mención de Diana es a sus perros, ya citada; Minerva aparece una vez con su lechuza, otra en "Himno al estudiante":

Tú no das, como otrora Minerva, pulcro acero de sino triunfal, para herir la soberbia impostura $\mathrm{y}$ vencer a los tigres del mal. (416)

Tampoco se ve mucho a Venus o Afrodita, la más cantada de todas las diosas. En "Leyendo a Silva", uno de los mejores poemas de Valencia, compuesto de coplas de maravillosa armonía, se encuentra a la diosa bajo su nombre de Citeres:

Alli, cual casto grupo de núbiles Citeres cruzaban en silencio figuras de mujeres que vivieron sus vidas, invioladas y solas como la espuma virgen que circunda las olas; (4)

El símil de la "espuma virgen" es feliz porque recuerda el famoso nacimiento de Afrodita, engendrada por la semilla de Cronos que, derramada en el océano, se convirtió en espuma. Más tarde en el poema hay una alusión al amante de Venus y la inmensa pena de la diosa al perderlo:

No manchará su lápida epitafio doliente; tallad un verso en ella, pagano y decadente,

digno del crespo Adonis en muerte de Afrodita: un verso como el hábito de una rosa marchita,

que llore su caída, que cante su belleza, que cifre sus ensueños, ique diga su tristeza! (8-9) 
Esta bella elegía a José Asunción Silva termina con unos versos que le colocan entre los dioses:

Así rindió su aliento, bajo un sitial de seda, el último nacido del viejo cisne y Leda. (9)

En la obra poética de Valencia no se desencadena un alud de alusiones mitológicas como en muchos poemas de Darío o de Julio Herrera y Reissig, donde deslumbra la mitología con su opulencia y belleza. El colombiano por lo común se atiene al comedimiento clásico. Lo que gana su poesía en moderación y plasticidad, quizá lo pierde en emoción. Si le comparamos con Dario en su empleo de la mitología, vemos que en lo emotivo, y en especial, en lo erótico, Valencia va muy a la zaga; pero no prescinde de sus emociones. ${ }^{18}$ A través de su obra poética Valencia pone de manifiesto su amor a la antigïedad y despliega un conocimiento fehaciente de la mitología, más hondo que el de la mayoría de los modernistas y que el de los poetàs contemporáneos hispanoamericanos.

George Schade, Universidad de Texas,

18 V. Max Hentiquez Urêna, Breve bistợa dẹt modernismo (México, 1954), págs. $312-313$. 